SISOMOS AMERICANOS

Revista de Estudios

Transfronterizos
Volumen XXI, número 2,

Julio-diciembre de 2021.

Recibido: 30 de junio de 2021.

Aprobado: 23 de septiembre de 2021.

\title{
Paradiplomacia e integración transfronteriza: las veranadas en los Altos Valles de Calingasta*
}

\author{
Para-diplomacy and cross-border integration: summer pasturing in the High \\ Valleys of Calingasta \\ Mariano Alvarez**
}

Instituto de Estudios Internacionales, Universidad Arturo Prat, Chile.

\begin{abstract}
Resumen
La trashumancia de los crianceros de Coquimbo (Chile) hacia los Altos Valles de Calingasta (San Juan, Argentina) es un caso único en el continente americano, por su antigüedad y por los vínculos de integración y cooperación transfronteriza que involucra. Se trata de una práctica ancestral, llevada a cabo por un sector económico muy humilde y que se ha sostenido a lo largo de los años gracias a la integración social, económica y cultural que comparten Coquimbo y San Juan. Sin embargo, la historia reciente de las veranadas no está libre de dificultades, ya que fueron interrumpidas por más de una década -entre 2001 y 2013-, postergadas en 2019 y nuevamente interrumpidas en 2020. El artículo explora la experiencia de la reapertura en 2013, los debates y efectos de su postergación en 2019 y el impacto de la pandemia COVID-19 en 2020. El objetivo es relevar la voluntad de integración y cooperación transfronteriza entre Coquimbo y San Juan, la que se plasma en el accionar paradiplomático que ambos gobiernos subestatales efectuaron en la
\end{abstract}

\footnotetext{
${ }^{*}$ El artículo recoge y expande parte del trabajo realizado para la tesis doctoral del autor, con financiamiento de la Comisión Nacional de Investigación Científica y Tecnológica (CONICYT) de Chile.

** Doctor, Universidad de Leiden. Magíster en Estudios Internacionales, Universidad de Chile. Licenciado en Relaciones Internacionales y en Ciencias Políticas, Pontificia Universidad Católica Argentina. Investigador asociado al Instituto de Estudios Internacionales de la Universidad Arturo Prat. Director ejecutivo de la Red de Expertos en Paradiplomacia e Internacionalización Territorial (REPIT). Correo electrónico: marianoalv@gmail.com ORCID: 0000-0003-4367-2918
}

Cómo citar este artículo: Álvarez, M. (2020). Paradiplomacia e integración transfronteriza: las veranadas en los Altos Valles de Calingasta. Si Somos Americanos. Revista de Estudios Transfronterizos, 20(2), 70-93. doi: 10.4067/S0719-09482021000200070 
búsqueda soluciones. Para ello, el artículo utiliza fuentes primarias -actas, prensa y entrevistas a informantes claves-, así como bibliografía secundaria de contexto.

Palabras clave: integración transfronteriza, veranadas, trashumancia.

\begin{abstract}
The transhumance of goat breeders from Coquimbo (Chile) in the High Valleys of Calingasta (San Juan, Argentina) is a unique case in the American continent due to its long history and the integration and cross-border cooperation links involved. This is an ancestral practice carried out by a very humble economic sector, and one that has been sustained over the years thanks to the social, economic, and cultural integration of Coquimbo and San Juan. However, the recent practice of summer pasturing was interrupted for more than a decade -between 2001 and 2013-, postponed in 2019 and again interrupted in 2020. This article explores the experience of the reopening in 2013, the debates and effects of its postponement in 2019 and the impact of the COVID-19 pandemic in 2020. The objective is to highlight the will for integration and cross-border cooperation between Coquimbo and San Juan, which is reflected in the para-diplomatic actions undertaken by both sub-state governments in the search for solutions. The article draws on primary sources - proceedings, news articles and interviews with key informants-, and a secondary bibliography to provide context.
\end{abstract}

Keywords: cross-border integration, summer pasturing, transhumance.

\title{
Introducción
}

La trashumancia llevada a cabo por los crianceros de la región chilena de Coquimbo en los Altos Valles de Calingasta de la provincia argentina de San Juan es considerada por muchos como un caso único y emblemático en el continente americano. Se trata de una práctica ancestral, llevada a cabo por un sector económico muy humilde y que se ha sostenido a lo largo de los años gracias, en gran medida, al vínculo de integración social, económica y cultural que comparten Coquimbo y San Juan. En este sentido, los intereses y prioridades de los países no han estado siempre en línea con las motivaciones locales, por ello, la paradiplomacia ejercida por ambos gobiernos no centrales es un excelente ejemplo de cooperación transfronteriza. ${ }^{1}$

Las veranadas se desarrollaron de manera regular durante cuatro siglos, pero en los últimos veinte años fueron interrumpidas entre 2001 y 2013, postergadas en 2019 y nuevamente interrumpidas en 2020. Estos hitos son excepciones en una práctica que involucra la cooperación transfronteriza y que permite observar cómo respondieron ante ellos los gobiernos no centrales y los Estados. En

\footnotetext{
${ }^{1}$ Entrevista a Juan M. Fuenzalida, exintendente de Coquimbo. La Serena (24 de noviembre de 2014). Entrevista a Marcelo Fretes, secretario de Relaciones Institucionales del Gobierno de San Juan (videollamada, 24 de junio de 2021).
} 
ambas interrupciones, la política nacional no tomó en consideración la dimensión del impacto que el cierre de fronteras tenía sobre la economía regional, así como tampoco propuso soluciones al respecto. Fue el accionar de los actores locales el encargado de salvaguardar los intereses de los crianceros, a través de proponer y encontrar soluciones a las barreras levantadas.

Entendiendo la paradiplomacia como "el involucramiento de los gobiernos no centrales en asuntos exteriores, de forma directa o indirecta, en actividades permanentes o ad hoc, en la persecución de objetivos funcionales"(Alvarez, 2021, en prensa), las acciones llevadas a cabo por los gobiernos de Coquimbo y San Juan, respecto de las veranadas, pueden ser consideradas como un claro ejemplo del rol que la acción externa de los gobiernos no centrales cumple en la solución de problemas transfronterizos de interés local.

El artículo explora la experiencia del cierre de las veranadas en 2001, los debates y efectos de su postergación en 2019 y el impacto sobre estas a raíz del cierre de fronteras en 2020. El objetivo principal es relevar el rol del accionar paradiplomático en la búsqueda de la solución del problema transfronterizo. Para ello se emplean fuentes primarias: actas, prensa y entrevistas a informantes claves y bibliografía secundaria - escasa en esta temática- como apoyo al contexto en que se desarrollan las veranadas. ${ }^{2}$ A esta introducción siguen cuatro secciones: la primera presenta la génesis de las veranadas como elemento transfronterizo. La segunda aborda su interrupción en 2001, a razón del brote de fiebre aftosa en Argentina. La tercera relata el impacto de la crisis hídrica en la postergación de 2019. La cuarta estudia los efectos de la pandemia COVID-19 en la suspensión de la actividad en 2020. El artículo termina con una conclusión respecto del rol que la paradiplomacia transfronteriza jugó en cada uno de los períodos analizados.

\section{Génesis de las veranadas como elemento transfronterizo}

La trashumancia en los Altos Valles de Calingasta es una actividad histórica, cuya génesis se remonta al siglo XVI, con la llegada de los primeros carneros a la zona central de Chile (véase Maino, 2015). Desde entonces, el ganado caprino se concentra en los valles del Limarí y Choapa, en cuyas zonas se asientan los crianceros durante la mayor parte del año; sin embargo, al llegar el verano, el ganado es trasladado a los valles intercordilleranos, cuyas pasturas y aguas hacen que las cabras produzcan el doble que cuando se encuentran en las zonas bajas. ${ }^{3}$

La actividad se desarrolló de manera ininterrumpida en los siglos de dominio español y luego de las independencias de Argentina y Chile. Durante el período de consolidación nacional de ambos países, se impuso el principio de cordillera libre, que permitía la circulación de personas y mercancías en la zona fronteriza, y que fue ratificado entre 1810 y 1828 . Durante esta etapa, las relaciones a nivel de gobierno central eran muy positivas en cuanto a la integración e, incluso, se

\footnotetext{
${ }^{2}$ Las entrevistas tuvieron lugar en 2014, 2016 y 2021 de forma oral. Previo a iniciar el intercambio, se solicitó un consentimiento oral al entrevistado o entrevistada, para lo cual se explicitó el propósito de la entrevista.

${ }^{3}$ Entrevista a Juan C. Codoceo, presidente de la Asociación Provincial de Crianceros del Limarí (llamada telefónica, 23 de febrero de 2016).
} 
intentó cristalizar el principio de cordillera libre en el Tratado de 1826 y en una unión aduanera (Lacoste, 1999, 2005). Si bien estos intentos institucionales no prosperaron, la actividad en los Altos Valles de Calingasta continuó desarrollándose sin inconveniente, debido a que el límite no era planteado como tal y porque los Estados estaban más enfocados en consolidar su independencia y organización nacional (Lacoste, 2003). Asimismo, si bien la circulación era libre, no existía un alto tránsito en la cordillera, debido a la inexistencia de rieles o carreteras. Lo que existía era precisamente la actividad de los arrieros, troperos y crianceros, la que se transformó en protagonista del vínculo de integración transfronteriza (Iribarren Avilés, 2012).

A partir de la década de 1840, se inició la consolidación geográfica de Argentina y Chile y se volvió imperativa su delimitación efectiva, lo que generó un primer punto de conflicto. En dicha oportunidad, se discutió la jurisdicción sobre el Estrecho de Magallanes y los fértiles valles intercordilleranos; estos últimos eran precisamente el sector donde se producían las veranadas. El conflicto comenzó en 1846, cuando un comandante argentino decidió despachar tropas a los valles, a fin de cobrar un impuesto a los ganaderos chilenos que habían llevado sus animales a pastar a la zona. Si bien esta acción no generó mayor conflicto, debido a que el Estado de Chile concentraba su atención en otros temas, sí propició cierta incertidumbre respecto a por dónde pasaba exactamente el límite (véanse De Irigoyen, 1881; Orrego Luco, 1902). El Tratado de 1856 buscó poner los fundamentos para definir correctamente el límite, al tiempo que impulsó la libre navegación y circulación de bienes y personas, fortaleciendo el principio de cordillera libre (Fortin de Iñones, 2011).

En 1881 se firmó el Tratado de Límites, el cual sentó los principios sobre la base de los cuales se procedería a la demarcación. El acuerdo estableció que el límite entre Argentina y Chile serían "las cumbres más elevadas de dicha Cordillera que dividan las aguas y pasará por entre las vertientes que se desprenden a un lado y otro" (República Argentina y República de Chile, 1881, p. 2); este doble criterio generó conflicto entre los peritos designados por cada país (Dugini de De Cándido, 1997). Sin embargo, para finales del siglo XIX se lograron acordar la amplia mayoría de los hitos limítrofes y someter a arbitraje aquellos restantes (Ygobone, 1971).

Una vez definido el límite, este solucionó los diferendos a nivel de países, pero generó una situación complicada para la trashumancia en los Altos Valles de Calingasta. Los criterios de más altas cumbres y divisorias de aguas coinciden en la mayoría de los hitos limítrofes, pero ciertos condicionamientos geográficos propios de la cordillera de los Andes hicieron que existiesen sectores donde los criterios se distancian. Uno de los sectores donde los criterios no coinciden, es parte del límite entre la actual Región de Coquimbo y la Provincia de San Juan, donde se crearon sectores intercordilleranos - los Altos Valles de Calingasta- que quedaron atrapados entre las altas cumbres al este y la divisoria de aguas al oeste (véase Figura 1). Como consecuencia, se encuentran 
del lado argentino, pero son accesibles únicamente para el ganado proveniente de Chile (Véliz Codina, 2011). ${ }^{4}$

Figura 1: Zona de veranadas en los Altos Valles de Calingasta

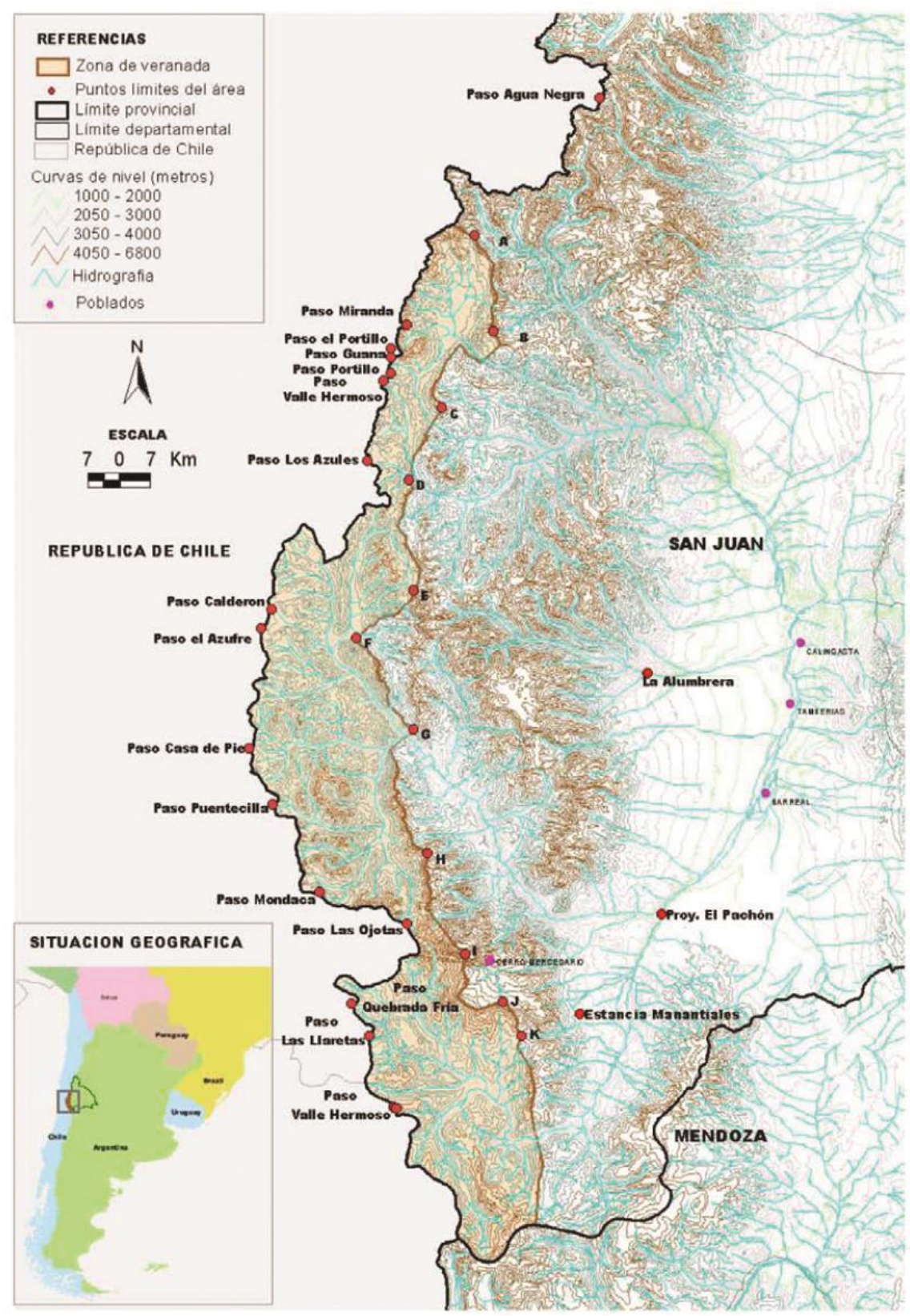

Fuente: Resolución 258/2013 del Servicio Nacional de Sanidad y Calidad Agroalimentaria (SENASA) de Argentina.

\footnotetext{
${ }^{4}$ Entrevista a Mónica Dinucci, directora de Límites y Fronteras del Ministerio de Relaciones Exteriores de Argentina, Buenos Aires (14 de noviembre de 2014). Entrevista personal a José Luis Gioja, gobernador de San Juan, San Juan (3 de diciembre de 2014).
} 
Sin embargo, se trata de una zona donde existió un frecuente tránsito ya desde la época de la conquista y colonización (Iribarren Avilés, 2012; López Daneri y Davire de Musri, 2006), lo cual generó un importante intercambio comercial y de ganado que propició el establecimiento de relaciones familiares. ${ }^{5}$ El vínculo formado por lazos de sangre, culturales y económicos entre las comunidades de Coquimbo y San Juan favoreció el normal desarrollo de la actividad, una vez establecido el límite.

Llegada la década de los noventa, ${ }^{6}$ las veranadas se repetían de forma normal todos los años. Prueba de ello se encuentra en cómo abordan la temática las actas de los primeros ocho encuentros del Comité de Frontera Paso de Agua Negra. Desde el primer encuentro en 1996, los Comités se constituyeron en la institución donde se fijaban los criterios para las veranadas, a razón de lo cual las comisiones y subcomisiones reconocían el éxito de la actividad y la colaboración interinstitucional para garantizar y proteger a los crianceros, abordando tanto situaciones climáticas adversas como los problemas de salud que pudiesen tener lugar. Dentro de los Comités, las veranadas eran tratadas por los organismos centrales como algo meramente administrativo, aunque para 1999 ya participaban de la Subcomisión de Agricultura, Ganadería y Veranadas representantes del sector público y privado de Coquimbo y San Juan (VI Reunión del Comité de Fronteras "Paso Agua Negra", 1999).

Respecto de su relevancia, en materia social las veranadas afectan a un grupo cercano a las trescientas personas. ${ }^{7}$ En cuanto a su impacto económico, antes de la primera interrupción, el canon de ingreso por cabeza de ganado caprino era de US\$ 2,4 (VI Reunión del Comité de Fronteras "Paso Agua Negra", 1999) y subían cerca de cien mil cabras. Cuando se regularizaron las veranadas, se autorizó el ingreso de 78 mil cabezas de ganado menor y 2.350 de ganado mayor, con un canon de US\$ 4,5 y 20, respectivamente (Acta del Acuerdo de "Reunión Técnica de Veranadas", 2013). En la temporada 2018-2019, se autorizó un aumento en el número de cabezas, llegando a ochenta mil de ganado menor y 2.500 de ganado mayor (VII Acta del Acuerdo de «Reunión Técnica de Veranadas», 2018). Es decir que, antes de la primera suspensión, las veranadas dejaban en San Juan cerca de los US\$ 250 mil, pero luego de regularizadas, se transformaron en un aporte de US\$ 400 mil anuales. En 2019, el canon se elevó a 5,5 para ganado menor y US\$ 25 para ganado mayor, pero el número de cabezas se redujo en las temporadas 20192020 y 2020-2021, dejando a la provincia US\$ 310 mil y 127 mil, respectivamente (VIII Acta del Acuerdo de "Reunión Técnica de Veranadas", 2019; XI Acta del Acuerdo de "Reunión Técnica de Veranadas", 2020).

Parte de la disparidad entre el interés que los gobiernos nacionales y locales tienen sobre las veranadas, se explica por la relevancia social y económica de estas. El tránsito ganadero otorga

\footnotetext{
${ }^{5}$ Entrevista a Adriana Peñafiel, exalcaldesa de La Serena y exdirectora regional del Servicio Nacional de Turismo de Chile, La Serena (18 de noviembre de 2014).

${ }^{6}$ Para mayores detalles respecto a la naturaleza jurídica, organización y evolución de los Comités de Frontera y Comités de Integración, véase Alvarez $(2019,2020)$.

${ }^{7}$ Entrevista a Marcelo Fretes
} 
beneficios tanto a los crianceros chilenos, que acceden a buenas pasturas para su ganado, como a los sanjuaninos, que reciben una compensación por el uso de sus tierras. Sin embargo, por una cuestión de escala, el impacto de la actividad a nivel nacional es nulo. Se trata entonces de un sector de tierra limitado, al cual accede un grupo económico pequeño y humilde, generando una situación de alta importancia para Coquimbo y San Juan, pero de relevancia prácticamente nula para los Estados.

\section{Interrupción por fiebre aftosa en 2001}

En 2001, se produjo el primer cierre oficial de las veranadas, desprotegiendo a los crianceros y poniendo en riesgo el sector económico local. Ello ocurrió por decisiones emanadas desde el centro político de los países, sin dar cabida a los reclamos de los gobiernos de Coquimbo y San Juan. No obstante, fueron estos los que impulsaron la solución al cierre.

La cancelación de las veranadas fue el resultado de la conjunción de dos sucesos, uno en cada país. Por un lado, durante la década de 1990 Chile había llevado a cabo una fuerte política de internacionalización de su economía, a través de la firma de una cantidad importante de acuerdos de libre comercio, respecto de los cuales una de las garantías que Chile ofrecía era su condición fito y zoosanitaria, la cual se beneficiaba de la aislación natural que el país tiene en el ámbito geográfico. ${ }^{8}$ Por otro lado, la evolución en la lucha contra el virus de la fiebre aftosa en Argentina, el cual se encuentra erradicado en Chile, sufrió un fuerte revés.

Las condiciones zoosanitarias de Argentina siempre habían estado presentes en las conversaciones sobre las veranadas. En el primer Comité de Frontera Paso de Agua Negra (I Reunión del Comité de Frontera "Paso Agua Negra", 1996), el delegado del Servicio Agrícola y Ganadero de Chile (SAG) hizo notar cierto distanciamiento con la actividad, declarando que Chile aceptaba las veranadas únicamente porque se reconocía a los Altos Valles de Calingasta como libres de fiebre aftosa. Sin embargo, en el segundo Comité de Frontera (II Reunión del Comité de Frontera "Paso Agua Negra", 1997), el SAG solicitó que se aclarase que el reconocimiento de zona libre de fiebre aftosa solo podía hacerlo la autoridad central. Como este era efectivamente el caso, la actividad continuó desarrollándose sin inconvenientes, lo cual se vio favorecido en el 2000, cuando la Oficina Internacional de Epizootias (OIE) - actual Organización Mundial de Sanidad Animalreconoció a la Argentina como país libre de aftosa sin vacunación.

El problema se ocasionó poco después, en julio de 2000, cuando ingresaron a la Argentina, desde el Paraguay, animales bovinos no declarados e infectados con el virus de la fiebre aftosa. Si bien se logró controlar la enfermedad, la Argentina tuvo que aplicar nuevamente vacunación, lo cual implicó un cambio de estatus por parte de la OIE. La organización internacional modificó la condición sanitaria por la de país libre de fiebre aftosa con vacunación. ${ }^{9}$ Chile, por su parte,

\footnotetext{
${ }^{8}$ Entrevista a Mónica Dinucci.

${ }^{9}$ Para mayores detalles, véase Pecker (2007).
} 
mantuvo el estatus de país libre de aftosa sin vacunación, pero debió endurecer sus políticas de tránsito animal con la Argentina para salvaguardar la condición zoosanitaria del país.

Debido a este cambio en el estatus de la Argentina, se prohibió el cruce de ganado y se procedió a vedar las veranadas y despoblar una franja territorial desde el límite político hacia el interior de Chile. Esto fue informador por el SAG y por Carabineros de Chile, en septiembre de 2001, durante el décimo comité de frontera (X Reunión del Comité de Frontera "Paso Agua Negra", 2001). Bajo las nuevas restricciones, cualquier animal chileno que cruzase a territorio argentino debía ser sacrificado al regresar a Chile; a su vez, se la aplicaría una multa al criancero.

La prohibición desconocía el impacto económico y social que implicaba para la zona, lo cual generó una situación de irregularidad. Durante el verano, las cabras suben naturalmente a los Altos Valles, al tiempo que la práctica es una tradición ancestral fundamental para la economía de los crianceros. Debido a ello, las veranadas continuaron desarrollándose, pero en la clandestinidad y con altos riesgos, ${ }^{10}$ ocasionando serios problemas con las autoridades centrales de ambos países.

El límite entre Coquimbo y San Juan es atravesado por quince pasos fronterizos, según acordaron Argentina y Chile en el "Primer Acuerdo Complementario del Acuerdo sobre Coordinación de Apertura y Cierre de Pasos Fronterizos", firmado en 1996. De ellos, solamente el de Agua Negra es vehicular, los restantes son pasos de apertura temporal para la utilización exclusiva de los arrieros. ${ }^{11}$ Cuando el SAG prohibió las veranadas, los catorce pasos temporales dejaron de habilitarse y, si bien no fueron eliminados en el "Segundo Acuerdo Complementario del Acuerdo sobre Coordinación de Apertura y Cierre de Pasos Fronterizos", firmado en 2002, los servicios de control fronterizo dejaron de funcionar. Como consecuencia de ello, los crianceros que igualmente decidiesen cruzar hacia los Altos Valles lo hacían sin ninguna supervisión ni contención especializada, a la vez que no contaban con los correspondientes papeles migratorios, aduaneros y sanitarios.

Del lado argentino, la trashumancia no estaba prohibida por el Servicio Nacional de Sanidad y Calidad Agroalimentaria (SENASA); el problema era que los crianceros cruzaban sin la debida autorización de ingreso; es decir, la Argentina no tenía ninguna prohibición de que se realizasen las veranadas, siempre y cuando hubiese una declaración migratoria y aduanera de por medio. Al no estar habilitados los pasos, Gendarmería argentina procedía a expulsar a los crianceros del país, generándole a estos últimos un altísimo costo, el cual era agravado al regresar a Chile -ya fuese por el fin de las veranadas o por la expulsión de Gendarmería-, porque si eran descubiertos por los servicios fronterizos chilenos, sus animales eran sacrificados y debían pagar una multa. ${ }^{12}$

El SAG tenía pleno conocimiento de que no existía posibilidad de fiebre aftosa en los Altos Valles de Calingasta, pero igualmente la política nacional no fue permeable a las voces locales y optó por

\footnotetext{
${ }^{10}$ Entrevista a J. L. Gioja. Entrevista a J. C. Codoceo.

${ }^{11}$ Entrevista a Eduardo Guerci, director de Vialidad Provincial de San Juan, San Juan (5 de diciembre de 2014).

${ }^{12}$ Entrevista a Elena Peletier, secretaria de Relaciones Institucionales del Gobierno de San Juan, San Juan (2 de diciembre de 2014).
} 
desproteger a los crianceros. ${ }^{13}$ Estos siempre insistieron en que el ganado de Argentina no accedía a los valles intercordilleranos utilizados por los crianceros chilenos y, en consecuencia, no existía una posibilidad real de contagio de fiebre aftosa durante las veranadas. Sin embargo, el SAG se negó permanentemente a escucharlos. ${ }^{14}$

La paradiplomacia transfronteriza comenzó a operar inmediatamente y, desde el XI Comité de Frontera, realizado en 2002, se comenzó a solicitar al SAG y al SENASA que se reuniesen para analizar la situación sanitaria (XI Reunión del Comité de Frontera "Paso Agua Negra", 2002). Ante esta solicitud, en 2003, el organismo de Chile respondió que no se habían llevado a cabo las reuniones por falta de la contraparte de Argentina, pero que igualmente no habría modificado su postura, ya que la prohibición no se alteraría si primero no lo hacía el estatus sanitario de Argentina (XII Reunión del Comité de Frontera "Paso Agua Negra", 2003).

La situación se agravó en 2004, debido a que el jefe de Gendarmería de la Argentina que realizó la inspección de rutina de los Altos Valles de Calingasta, al encontrar a los crianceros, no procedió a su expulsión, sino al secuestro de las cabras, derivando el caso a la justicia federal del país. En dicha ocasión, la entonces senadora por la región de Coquimbo, Evelyn Matthei, se comunicó directamente con el gobernador de San Juan, José Luis Gioja, para buscar una solución. La autoridad provincial instruyó a su secretaria de Relaciones Institucionales, Elena Peletier, para que realizase las gestiones pertinentes, a fin de resolver la situación entre las autoridades locales. Gracias a ello, se logró que las cabras fuesen repuestas a sus propietarios.

El incidente de 2004 puso en relevancia la necesidad de una solución de fondo al problema. Por ello, ese mismo año, la gobernadora de la provincia chilena de Elqui pidió una reunión especial para tratar el tema delas veranadas, pero no solo con los servicios centrales sino con todos los actores involucrados (XIII Encuentro del Comité de Frontera "Paso Agua Negra", 2004). Esto permitió la incorporación de las principales voces interesadas, pero produjo un clima de alta complejidad, debido a que se enfrentaban normas de los gobiernos centrales con la práctica local. ${ }^{15}$ Al año siguiente se comenzó a tratar el tema también en los comités transfronterizos, ${ }^{16}$ entendiéndolos como el foro donde las voces locales podían proponer una solución. Durante los siguientes cuatro comités se solicitó la pronta solución del problema. Ante estos requerimientos, el SAG se limitó a reiterar que nada cambiaría hasta que no lo hiciese el estatus sanitario de Argentina (XIV Encuentro del Comité de Frontera "Paso Agua Negra", 2005; XV Encuentro del Comité de Integración "Paso Agua Negra", 2006; XVI Comité de Integración Internacional "Paso Agua Negra", 2007; XVII Comité de Integración "Paso Agua Negra", 2008).

Debido a la centralización de las decisiones de política exterior y sanidad -en especial en Chile, debido a su forma de Estado unitaria- fue necesario hacer reuniones por separado entre los

\footnotetext{
${ }^{13}$ Entrevista a E. Peletier.

${ }^{14}$ Entrevista a J. C. Codoceo.

${ }^{15}$ Entrevista a E. Peletier.

${ }^{16}$ Hasta 2005, los foros se denominaban "Comités de Frontera"; a partir de 2006, el nombre mutó a "Comités de Integración".
} 
gobiernos no centrales y los ministerios de Relaciones Exteriores y organismos centrales involucrados. Finalmente, se logró que el SENASA hiciese una presentación ante la OIE solicitando que se regionalizase el estatus zoosanitario de la Argentina y que se declarara a los Altos Valles de Calingasta como libres de aftosa sin vacunación. Para esto, el accionar de la paradiplomacia transfronteriza fue fundamental, debido a que la solicitud no surgió desde el organismo central. La propuesta la hicieron los propios crianceros chilenos al gobernador de San Juan, en 2008, solicitando que se generase una zona de exclusión sanitaria en los valles en cuestión.

A fines de 2009, el SENASA aceptó realizar la presentación ante la OIE (XVIII Comité de Integración, 2009) y, el año siguiente, comunicó que estaba trabajando en la propuesta y solicitó que se realizase una reunión con todos los actores involucrados; no bajo la coordinación de un organismo del gobierno central, sino al amparo del gobierno provincial de San Juan (XIX Comité de Integración "Paso Agua Negra", 2010). Para 2011, la Subcomisión de temas fitozoosanitarios y veranadas tuvo una participación mayoritaria de funcionarios de los gobiernos de Coquimbo y San Juan. Fue en dicho foro que el SENASA anunció que había realizado la presentación ante la OIE. A razón de ello, las subcomisiones de Migraciones y Controles Fronterizos, así como la Comisión de Medio Ambiente, comenzaron los trabajos preparatorios para las veranadas (XX Comité de Integración "Paso Agua Negra", 2011).

La reapertura de las veranadas parecía cercana; sin embargo, la solución había sido propuesta desde el ámbito local, por lo que los organismos centralizados no estaban completamente permeados de ella. Esto generó una dificultad que complicó nuevamente el proceso. El procedimiento de regionalización de la OIE implica diversas etapas. Una primera es la solicitud del país afectado - la cual hizo el SENASA de Argentina- y la tercera es la comprobación en terreno de las condiciones. La etapa intermedia consiste en la manifestación de interés por parte del país involucrado -Chile-, ya que, si no hay una contraparte interesada en la regionalización, no tiene sentido realizarla. Cuando la OIE consultó a Chile respecto de si el país estaba interesado en la regionalización de Argentina, la consulta fue derivada al personal del SAG, el cual, desconociendo el compromiso que la organización había asumido en la reunión de enero de 2010, respondió de forma negativa. En consecuencia, la OIE resolvió que no iba a someter el cambio de estatus de los Altos Valles de Calingasta a trabajo en comisión, debido a que Chile no tenía interés. A razón de esto, el SENASA suspendió la presentación, a la vez que mostró su indignación por cómo había quedado la institución frente a la OIE. ${ }^{17}$

En el Comité de Integración de 2012, el SENASA notificó formalmente la suspensión de la presentación. Sin embargo, nuevamente el foro se constituyó en articulador de soluciones y se acordó realizar una reunión en Buenos Aires con todos los interesados (XXI Encuentro del Comité de Integración "Paso Agua Negra", 2012). En esta oportunidad se incorporó otro actor del nivel central de Chile, ya que la Dirección de Fronteras y Límites del Estado (DIFROL) del Ministerio

\footnotetext{
${ }^{17}$ Hasta 2005, los foros se denominaban "Comités de Frontera"; a partir de 2006, el nombre mutó a "Comités de Integración".
} 
de Relaciones Exteriores recogió el tema, ${ }^{18}$ con ello se logró que el Ministerio de Relaciones Exteriores y la Presidencia del país instruyesen al SAG para dar el visto bueno al pedido que la Argentina volvería a presentar ante la OIE.

Gracias a este acuerdo, la OIE comenzó los trabajos en comisión y, en mayo de 2013, certificó a los Altos Valles de Calingasta como zona libre de aftosa sin vacunación. Consiguientemente, las subcomisiones de Migraciones, Aduanas, Controles Fronterizos y Temas Fito y Zoosanitarios, así como la Comisión de Medio Ambiente del XXII Comité de Integración, comenzaron a prepararse para la veranada 2013-2014, la primera oficialmente reconocida en más de una década (XXII Encuentro del Comité de Integración "Paso Agua Negra", 2013).

\section{Postergación por crisis hídrica en 2019}

Junto con la regionalización de los Altos Valles de Calingasta, se procedió a la formalización de la trashumancia a través de institucionalizar el mecanismo de coordinación en el Acta de Acuerdo de la Reunión Técnica de Veranadas, firmada el 1 de octubre de 2013 por las autoridades de la Provincia de San Juan y la Región de Coquimbo, así como por representantes de los ministerios de Relaciones Exteriores de Argentina y Chile, y promulgada con fuerza de ley por la Cámara de Diputados de la Provincia de San Juan (Acta del Acuerdo de Reunión Técnica de Veranadas, 2013). Durante los siguientes cinco años, las veranadas se desarrollaron de manera normal. Sin embargo, la crisis hídrica que afecta a la región binacional comenzó a profundizarse y a reducir la caída de nieve en los valles intercordilleranos. Esto produjo un fuerte impacto en su ecosistema, el cual no logra su completa recuperación de un año al otro. ${ }^{19}$ Debido a ello, en 2019 se estuvo a punto de cancelar las veranadas.

La trashumancia en los Altos Valles de Calingasta requiere una enorme coordinación de instituciones desde el lado chileno. Ello no solo responde a la pluralidad de actores involucrados, sino también a la naturaleza jurídica de estos, debido a que Chile es un país unitario centralizado y con una desconcentración regional a través de secretarías ministeriales. Por ello, muchas de las instituciones involucradas no responden jerárquicamente al gobierno regional. ${ }^{20}$

Para lograr la coordinación necesaria, existe un protocolo a seguir (División de Planificación Regional, 2020), a razón del cual, por ejemplo, se le solicita a Aduanas de Chile que especifique las tornaguías que se solicitarán; al SAG que actualice el certificado zoosanitario de exportación y el formulario de movimiento animal, así como la coordinación con el SENASA para las vacunas solicitadas por la autoridad argentina; a Carabineros que informe cuáles serán los destacamentos fronterizos efectivamente habilitados; a Policía de Investigaciones (PDI) que actualice el formato para solicitar el salvoconducto, así como las condiciones y fechas límites del cruce. Asimismo, se

${ }^{18}$ Entrevista a Iván Páez, jefe de la Unidad de Asuntos Internacionales de la DIFROL, Santiago (28 de noviembre de 2014).

${ }^{19}$ Entrevista a M. Fretes.

${ }^{20}$ Para más detalles, véase Alvarez (2019). 
deben realizar coordinaciones entre los mismos servicios, porque no todos se hacen presente en la frontera; en su lugar, capacitan y delegan su función en Carabineros. Finalmente, se debe capacitar a los crianceros en materia de medioambiente, para que estos cumplan con los requisitos que establezca la autoridad argentina respecto del cuidado de la flora, fauna y recursos hídricos, así como en el tratamiento de la basura. En definitiva, todos los servicios que tienen vinculación con las veranadas deben coordinarse, lo cual implica un largo y detallado trabajo que comienza en el mes de junio. $^{21}$

Por otro lado, también son necesarias coordinaciones interinstitucionales en la Provincia de San Juan, que, si bien son de complejidad distinta debido al régimen federal del país, también implican tiempo y trabajo. Antes de realizarse la reunión técnica de veranadas -instancia en la que se establecen los requisitos de ingreso, el número de cabezas, el canon y demás detalles de la actividad-, el gobierno de San Juan debe recibir la información respecto del monitoreo de los valles intercordilleranos para conocer cuál es el desarrollo de las pasturas y cómo ha sido la publiometría y nievemetría. Esto implica recibir insumos desde distintas instituciones -tanto provinciales como nacionales- para determinar cuál será la carga animal autorizada a ingresar a las veranadas. Por ello, la coordinación entre los dos gobiernos subestatales comienza en julio.

En 2019, la situación hídrica en los valles de Coquimbo era apremiante y el gobierno regional le solicitó a la provincia argentina que se adelantase la fecha de ingreso a las veranadas. Esta se había mantenido en el primero de diciembre durante los últimos seis años, pero la región chilena ahora solicitaba que se adelantase a noviembre. Debido a la cercanía política y a la integración transfronteriza con Coquimbo, el gobierno de San Juan aceptó adelantar las veranadas, pero lo hizo sin haber recibido aún los informes técnicos de las respectivas instituciones. ${ }^{22}$

En octubre, se establecieron las ventanillas únicas en las gobernaciones de Limarí y Choapa para comenzar a recibir las solicitudes de los crianceros y hacer los contratos respectivos. En este momento llegó una comunicación del gobierno de San Juan, mediante la cual se solicitaba detener el proceso porque habían recibido los informes técnicos y se constataba un serio problema en la recuperación del ecosistema. A razón de ello, la provincia argentina anunciaba que se vería obligada a suspender las veranadas, de acuerdo con lo recomendado por los técnicos, durante al menos cinco años. ${ }^{23} \mathrm{La}$ situación hídrica era particularmente relevante, debido a que es precisamente en esos valles donde se encuentran las vertientes del río San Juan, único caudal de agua de consumo doméstico, agrícola e industrial de provincia homónima, pero iba incluso más allá y afectaba a todo el ecosistema de los valles. ${ }^{24}$

En este escenario, los consejeros regionales Marcelo Castagneto y Alberto Gallardo viajaron a San Juan en representación del gobierno regional de Coquimbo para participar en la doble jornada de

\footnotetext{
${ }^{21}$ Entrevista a Paulina Castillo, encargada del Departamento de Relaciones Internacionales de la Región de Coquimbo (videollamada, 18 de junio de 2021).

${ }^{22}$ Entrevista a P. Castillo.

${ }^{23}$ Entrevista a P. Castillo

${ }^{24}$ Entrevista a M. Fretes.
} 
trabajo de la VIII Reunión Técnica de Veranadas, junto con autoridades provinciales y nacionales de Argentina. Durante la reunión, los organismos especializados presentaron los argumentos objetivos respecto al estado de los valles, en particular sobre sus reservas de agua y desarrollo de la flora. De acuerdo con los expertos, era preferible que no se permitiese el ingreso de ningún animal, a fin de favorecer la recuperación de los campos (VIII Acta del Acuerdo de "Reunión Técnica de Veranadas", 2019). El escenario dejaba a San Juan sin un ingreso importante de divisas, pero favorecía la conservación de sus humedales; los crianceros chilenos, por otro lado, enfrentarían una situación mucho más complicada.

No obstante, la apremiante situación hídrica que afectaba a San Juan, primó el principio de integración y cooperación transfronteriza. Prueba de ello fue que Sergio Uñac, gobernador de San Juan, insistió en que el resultado debía proteger los recursos de la provincia argentina, al tiempo que ayudar a los crianceros de la región chilena; algo reconocido y celebrado por los consejeros regionales de Coquimbo (Ríos, 4 de noviembre de 2019). Gracias a esta actitud, el acta final de la reunión habilitó el ingreso del ganado caprino -no así el bovino ni ovino-, con una reducción en el número de cabezas autorizadas -bajó de 80 mil a solo 50 mil-y un alza en el canon de ingreso (Morales, 1 de noviembre de 2019).

El que San Juan haya permitido esta flexibilidad en el ingreso se debió exclusivamente al vínculo de amistad transfronterizo que une a Coquimbo con San Juan. ${ }^{25}$ El gobierno de la provincia argentina, tradicionalmente, reconoce que los crianceros de Coquimbo son el grupo de pastores trashumantes más antiguos de toda América del Sur, por lo que consideran a las veranadas como un tema cultural y de cooperación transfronteriza, antes que como una cuestión económica. ${ }^{26}$

La gestión paradiplomática realizada por los consejeros regionales ante las autoridades de San Juan permitió que las veranadas fuesen llevadas a cabo. No obstante, David Arancibia, presidente de la Asociación de Crianceros de Monte Patria, expresó que el cambio en la fecha de inicio de la trashumancia generó confusión y malestar entre los crianceros chilenos, no contra el gobierno de San Juan, sino contra el propio gobierno regional. En una entrevista con el diario El Día, Arancibia indicó que el gobierno de San Juan estaba en su derecho de cuidar sus humedales y evitar el sobrepastoreo y que el problema habría sido que nadie en el gobierno de Coquimbo les había avisado de la postergación en su debido momento (Varela, 4 de noviembre de 2019). Recién el 4 de noviembre -tres días después de la Reunión Técnica de Veranadas-, la Intendencia de Coquimbo comunicó a los crianceros el cambio en la fecha de inicio. Para entonces, ya había 39 autorizaciones para subir a los Altos Valles (Pizarro, 5 de diciembre de 2019), por lo que a 18 crianceros que ya habían ascendido a la cordillera y hecho sus trámites ante Carabineros de Chile, se les negó la entrada al territorio argentino (Varela, 4 de noviembre de 2019). Es posible que esta falta de comunicación no hubiese tenido lugar de haberse llevado a cabo el Comité de Integración

\footnotetext{
${ }^{25}$ Entrevista a P. Castillo.

${ }^{26}$ Entrevista a M. Fretes.
} 
2019, pero el mismo había sido suspendido debido al estallido social en Chile y las elecciones en Argentina (Alvarez, 2020).

La temporada partió finalmente el 15 de diciembre, lo cual complicó mucho a los crianceros, debido a que los animales se encontraban ya en mal estado por la falta de alimento y agua. En su momento, Juan Carlos Codoceo, presidente de la Asociación de Crianceros de Limarí y consejero regional de Coquimbo, aseguró que el 30\% de los animales que subiese en esas condiciones a las veranadas no regresarían (Pizarro, 5 de diciembre de 2019). A razón de ello, el gobierno de la Región de Coquimbo, en conjunto con el secretario regional ministerial de Agricultura y el Instituto de Desarrollo Agropecuario (INDAP) se abocó a entregar suplementos alimenticios maíz y soja- y a entablar conversaciones con el gobierno regional de Nuble para evaluar un posible traslado de animales a dicha zona (GORE Coquimbo, 4 de noviembre de 2019). Cuando el 20 de diciembre se cerró el ingreso a las veranadas, no habían logrado subir el total de los 50 mil animales autorizados. Sin embargo, ello no se debió a falta de tiempo, sino a falta de animales, ya que muchos habían muerto en el intertanto (Diario La Región de Coquimbo, 12 de enero de 2020).

Si bien las veranadas fueron finalmente habilitadas, gracias al trabajo paradiplomático realizado en la Reunión Técnica de Veranadas, la situación quedó en estado precario. Diez días antes de comenzar las veranadas, la planta de varilla -el principal alimento de las cabras- tenía solo un $25 \%$ de desarrollo y ya se encontraba florecida, con lo cual pronto perdería la hoja que es la parte que consume la cabra (Pizarro, 5 de diciembre de 2019). En este sentido, en el acta de la Reunión Técnica, San Juan se reservó el derecho de suspender las veranadas 2020-2021 para proteger los Altos Valles de Calingasta por las faltas de lluvia y de alimento (VIII Acta del Acuerdo de "Reunión Técnica de Veranadas", 2019).

Las perspectivas no mejoraron con el paso de los meses y, en enero de 2020, se anunció que, de no haber buenas lluvias durante el invierno, no se habilitarían las verandas a fines de dicho año (Diario La Región de Coquimbo, 12 de enero de 2020). Esto se profundizó cuando, en agosto, un comité de expertos de distintas especialidades aconsejó al gobierno de San Juan suspender las veranadas para preservar la zona donde se almacenan aguas subterráneas (Leiva, 22 de agosto de 2020).

\section{Interrupción por pandemia COVID-19 en 2020}

Después de la interrupción de 2001, las veranadas fueron retomadas en 2013 y se realizaron durante seis años ininterrumpidos. A pesar de la crisis hídrica que puso en jaque la temporada 2019-2020, la voluntad política y de integración transfronteriza primó. Todo parecía indicar que, en la medida en que la decisión pudiese ser tomada o influenciada por los actores subestatales, las veranadas se realizarían. Sin embargo, un nuevo factor externo y de manejo nacional hizo que la trashumancia en los Altos Valles de Calingasta se volviese a interrumpir. 
En diciembre de 2019, China sufrió el brote de un nuevo coronavirus denominado SARS-CoV-2, popularmente conocido como COVID-19. El virus resultó ser mucho más contagioso de lo previsto inicialmente y, para el 20 de enero, ya existían casos confirmados fuera de China, lo que hizo que la Organización Mundial de la Salud (OMS) declarase una emergencia sanitaria global a fines de dicho mes. A pesar de ello, el virus continuó expandiéndose $\mathrm{y}$, a principios de febrero, se produjeron las primeras muertes asociadas a COVID-19 fuera de China. Hacia fines de febrero, el virus llegó a América Latina y, en marzo, la OMS declaró que se trataba de una pandemia. A partir de ese momento, los países debieron afrontar una crisis sanitaria global, con nuevas variantes de COVID-19 generándose en distintos países. Una de las acciones que los Estados tomaron para proteger a sus poblaciones fue limitar, o incluso prohibir, el tránsito fronterizo.

Los primeros casos en Chile y Argentina se produjeron en marzo de 2020, lo cual generó un escenario de alta complejidad para la trashumancia en los Altos Valles de Calingasta. Por un lado, las veranadas resultaban imperiosas para los crianceros chilenos, debido a la crisis hídrica en que se encontraba la región y, por otro, implicaban la apertura de fronteras en medio de una pandemia global.

Si bien en Coquimbo eran conscientes de la posibilidad de suspensión de las veranadas, debido a la situación climática y al derecho de reserva con que contaba San Juan según el acta de la VIII Reunión Técnica de Verandas, se comenzó a analizar la realización de la trashumancia para la temporada 2020-2021. El gobierno de Coquimbo quería lograr una definición lo antes posible, debido a toda la logística involucrada en los distintos servicios que se deben coordinar y al apoyo que se debe prestar a los crianceros si no se producen las veranadas. ${ }^{27}$

Como a la incertidumbre por el tema hídrico se había sumado la pandemia, se comenzaron a llevar a cabo reuniones en el mes de julio, en particular aquellas referidas a la coordinación entre los distintos organismos involucrados del lado chileno (González, 28 de septiembre de 2020). Por el lado de la Provincia de San Juan, si bien el ecosistema no se había recuperado -la asesoría del Instituto Nacional de Tecnología Agropecuaria (INTA) así lo remarcaba-, existía la voluntad de habilitar un número menor de cabezas de ganado, tomando en consideración la grave sequía que continuaba afectando a los crianceros en los valles del Limarí y Choapa, a la cual se había sumado el impacto social y económico de la pandemia. ${ }^{28}$ Sin embargo, los meses se sucedieron sin una definición clara en ninguno de los dos frentes.

Llegado octubre, el recientemente nombrado intendente de la Región de Coquimbo, Pablo Herman, le dio prioridad al tema y convocó a una reunión de la tricomisión de Relaciones Internacionales, Medio Ambiente y Ordenamiento Territorial, del Consejo Regional. La sesión se realizó el 5 de noviembre, acordándose la necesidad de invitar al gobernador de San Juan y a sus ministros a un encuentro protocolar para resolver los temas de integración, entre los cuales se destacaban las veranadas y la apertura del Paso Agua Negra (González Lorca, 5 de noviembre de

\footnotetext{
${ }^{27}$ Entrevista a P. Castillo.

${ }^{28}$ Entrevista a M. Fretes.
} 
2020). Si bien la situación era de extrema urgencia para los crianceros de la región, los consejeros regionales insistieron, desde el primer momento, en que la solución debía de ser beneficiosa tanto para Coquimbo como para San Juan (El Montepatrino, 14 de octubre de 2020), como lo había sido el año anterior.

Para los primeros días de diciembre ya se habían realizado todas las reuniones de los distintos servicios públicos e institucionales vinculados con el tránsito fronterizo de la Región de Coquimbo (Región Binacional, 10 de diciembre de 2020) y se llevaron a cabo las negociaciones con el gobierno de San Juan, en las cuales el nivel central no participó. Los organismos técnicos del lado argentino se oponían a la actividad, debido a las condiciones en que se encontraban los Altos Valles de Calingasta y a su impacto en la situación hídrica de la provincia. Sin embargo, nuevamente primó el vínculo transfronterizo y el gobernador de San Juan consiguió que se firmase un acta (Armaza, 12 de diciembre de 2020; Navea, 15 de diciembre de 2020; Radio Montecarlo, 15 de diciembre de 2020). En ella se aclaró que, si bien la provincia argentina había hecho uso de su derecho reservado en el artículo 10 para suspender las veranadas, considerando la sequía por la que atravesaba la Región de Coquimbo, accedía al ingreso de 20 mil cabras a los Altos Valles, a partir del primero de enero de 2021. No obstante, el acta dejó en claro que aún faltaba resolver la apertura de los pasos terrestres, lo cual dependía de las autoridades centrales de ambos países (XI Acta del Acuerdo de Veranadas, 2020).

El gobierno regional de Coquimbo le pidió apoyo a la DIFROL para que se coordinase con su par de Argentina -la Dirección de Límites y Fronteras (DILYF)- respecto de la posibilidad de realizar la trashumancia en los Altos Valles de Calingasta. En un principio, desde el Ministerio de Relaciones Exteriores de Chile le comunicaron a Coquimbo que se esperaba poder habilitar los pasos fronterizos para las veranadas, debido a que existía la experiencia de los tres pasos habilitados para los trabajos de limpieza de la mina Pelambres y a que se trataba de áreas aisladas ${ }^{29}$ Por el lado del gobierno provincial de San Juan, se hizo una presentación formal al Ministerio del Interior -donde se aloja la Dirección Nacional de Migraciones (DNM)-, resaltando la tradición y necesidad de las veranadas y solicitando que se permitiese la realización de estas. ${ }^{30}$

Las diligencias llevadas a cabo por la región y la provincia no se habían limitado solo al acuerdo sobre la fecha, la cantidad de animales y las consultas a sus gobiernos centrales. Para autorizar las veranadas se estableció un estricto protocolo para la contención del COVID-19. A razón de ello, las autoridades regionales habían comenzado también con la preparación del mecanismo de ventanilla única para los trámites que los crianceros debían realizar (El Illapelino, 18 de diciembre de 2020). El panorama era alentador debido a que quien se encontraba al frente del Ministerio de Salud de Argentina era el exembajador de dicho país en Chile, Ginés González García, quien conocía y tenía una sensibilidad especial por la vinculación entre Coquimbo y San Juan. En dicho

\footnotetext{
${ }^{29}$ Entrevista a P. Castillo.

${ }^{30}$ Entrevista a M. Fretes.
} 
escenario, incluso se llegó a habilitar en la página web de la DNM de Argentina el formulario para solicitar el ingreso por los pasos de veranadas. ${ }^{31}$

La incertidumbre volvió a crecer con la aparición en el Reino Unido de la variante Alfa (B.1.1.7) del COVID-19, a razón de la cual la Argentina determinó, el 23 de diciembre, el cierre de sus fronteras hasta el 8 de enero (Diario Popular, 1 de enero de 2021). Para la primera semana de enero, ya todo estaba dispuesto entre los gobiernos de Coquimbo y San Juan, solo restaba que Chile y Argentina habilitasen los pasos fronterizos que se utilizan para la trashumancia hacia los Altos Valles de Calingasta. Sin embargo, la nueva variante del virus continuó expandiéndose y se hizo presente en Chile, por lo que, llegado el 8 de enero, la DNM de Argentina notificó que se extendía el cierre de las fronteras hasta, al menos, el 31 de enero (Leiva, 16 de enero de 2021). La prolongación del cierre de fronteras se hizo de forma general, incluyendo los pasos troperos y, con ello, las veranadas se suspendieron de forma irreversible.

Al igual que con el cambio de fecha en 2019, el reclamo de los crianceros fue la falta de participación en las decisiones. El presidente de la Asociación de Crianceros de Choapa, Héctor Báez, declaró al diario El Día que el gobierno regional les entregó poca información y falsas esperanzas sobre la realización de las veranadas, insistiendo en que se podría haber hecho una excepción, debido a la situación de aislamiento en que se producen las veranadas, y que la conversación no se desarrolló porque no hubo participación de los dirigentes locales (Varela, 13 de enero de 2021). Sin embargo, los gobiernos de Coquimbo y San Juan sí hicieron todas las diligencias posibles para la realización de las veranadas. Incluso, una vez confirmado el cierre de las fronteras, desde la provincia argentina continuaron intentando encontrar alternativas para mantener la colaboración transfronteriza, poniendo en contacto al gobierno de la región con empresas forrajeras de San Juan que estuviesen en condición de proveer el volumen de alimento necesario para los crianceros. ${ }^{32}$

\section{Conclusiones}

Los crianceros son personas de escasos recursos, por lo que su ganado es normalmente el único activo económico con el que cuentan. Ello hace de las veranadas una situación delicada y compleja para la Región de Coquimbo, pero social y económicamente de poco impacto a nivel nacional. Desde la perspectiva de la Provincia de San Juan, la situación es similar, donde la trashumancia hacia los Altos Valles de Calingasta tiene un impacto económico y de integración local, pero sin repercusiones a nivel del Estado argentino. Precisamente por ello, las veranadas son un ejemplo extraordinario de cooperación transfronteriza y de las motivaciones e importancia de la paradiplomacia.

\footnotetext{
${ }^{31}$ Entrevista a P. Castillo.

${ }^{32}$ Entrevista a M. Fretes.
} 
Durante la interrupción de 2001-2013, el centralismo en las decisiones zoosanitarias de Chile generó la suspensión de la actividad, pero el accionar subestatal logró que esta se resolviese. El SAG reconocía que las veranadas se llevaban a cabo de todas formas, pero se negaba a autorizarlas formalmente. ${ }^{33}$ Por ello, lo que se buscó desde el nivel subestatal fue que los Estados reconociesen su importancia y les otorgase un marco legal adecuado. ${ }^{34}$

Reflejo del accionar paradiplomático fue el hecho de que la primera autoridad chilena en abordar el problema de 2004, pese a su calidad de senadora, estableció contacto con el gobierno de la Provincia de San Juan en lugar de hacerlo con un par legislativo de nivel nacional. Posterior a ello, todo el trabajo de incidencia y búsqueda de soluciones se desarrolló a nivel del Comité de Integración, desde cuyo seno nació la propuesta para destrabar la actividad. Como indica Venegas (2019), los Comités de Integración han demostrado una mayor eficacia resolutiva respecto de las problemáticas de frontera, así como una gran resiliencia a los cambios políticos. Se trató entonces de un tema subestatal que no interesaba a los gobiernos centrales, pero que involucraba su política exterior y su reglamentación, y en la que la solución se buscó y encontró en un foro paradiplomático en el que los principales actores fueron los gobiernos no centrales. ${ }^{35}$

La postergación en 2019 es de una naturaleza distinta, debido a que los gobiernos centrales no estuvieron involucrados. La zona de veranadas es donde nacen las únicas aguas que tiene San Juan para el consumo humano, la agricultura y la industria, y los estudios científicos han demostrado que, al ser modificadas, ciertas vertientes se pierden hacia aguas subterráneas. ${ }^{36}$ En 2019, el ecosistema de los Altos Valles se encontraba en estado precario y requería de un descanso para poder recuperarse; sostener la presión de los animales y las personas en las veranadas podía ser muy perjudicial, ${ }^{37}$ y por ello San Juan optó por la suspensión.

El problema no era de regulación, económico, de comunicación o de cercanía entre las autoridades políticas; lo que estaba en riesgo era el ecosistema de los Altos Valles y el suministro de agua de San Juan. Sin embargo, la provincia argentina siempre ha sido muy sensible hacia el sector económico de los crianceros, debido a que ve las veranadas como un tema social de cooperación transfronteriza. Gracias a ello, la voluntad política permitió generar un espacio de diálogo para autorizar que un número menor, pero necesario, de cabezas de ganado ascendiese a las veranadas.

La interrupción de 2020 fue similar en naturaleza a la de 2001, pero distinta en su proceso de búsqueda de una solución. La pandemia COVID-19 obligó a los Estados a cerrar sus fronteras para controlar la expansión del virus y resguardar a las poblaciones. Ante dicho escenario, los gobiernos de Coquimbo y San Juan hicieron todos los esfuerzos posibles por preparar igualmente las veranadas, presentando los requerimientos y argumentos necesarios. Sin embargo, la decisión política y sanitaria del gobierno central finalmente fue el cierre. Considerando que existía un

\footnotetext{
${ }^{33}$ Entrevista a E. Peletier.

${ }^{34}$ Entrevista a Juan M. Sansó, diputado provincial de San Juan. San Juan, 2 de diciembre de 2014.

${ }^{35}$ Entrevista a J. M. Fuenzalida.

${ }^{36}$ Entrevista a P. Castillo.

${ }^{37}$ Entrevista a M. Fretes.
} 
antecedente de apertura excepcional de pasos fronterizos en la zona, para los trabajos de la mina Pelambres, es factible pensar que se podría haber implementado una excepción similar para las veranadas.

Las interrupciones de 2001 y 2020 tienen dos grandes contrastes que pueden haber condicionado el resultado. En primer lugar, existe una considerable diferencia respecto al lapso en que se desarrollan. Si bien la interrupción por fiebre aftosa fue finalmente resuelta, fueron necesarios doce años para ello; en el caso de la pandemia COVID-19, la determinación del cierre de fronteras por la nueva variante del virus se produjo en el momento en que debían habilitarse las veranadas. En segundo lugar, los foros de diálogo político transfronterizo establecidos en el Tratado de Maipú tanto el Comité de Integración como la Reunión Binacional de Gobernadores e Intendentes de la Frontera Común- no se llevaron a cabo en 2019 ni 2020, dificultando la generación de espacios para la resolución de los problemas transfronterizos.

Finalmente, es necesario un breve balance respecto a la relación de los gobiernos no centrales con otros actores y cómo ello afecta el proceso de integración transfronteriza. Por un lado, Coquimbo y San Juan han logrado desarrollar su integración y cooperación sin generar fricciones con los Estados, debido a que los servicios públicos centralizados actualmente -al menos en su generalidad- acompañan antes que buscan imponerse al trabajo paradiplomático. ${ }^{38}$ Esto ocurre, en gran medida, debido a la correcta vinculación de Coquimbo y San Juan con las instituciones del nivel central -como las direcciones de Fronteras y Límites. ${ }^{39}$

Por otro lado, el proceso de negociación de las veranadas aún dista de ser perfecto. Si bien los gobiernos no centrales están empoderados y son ellos los que negocian y resuelven, una de las principales debilidades estriba en que los crianceros no participan en las reuniones. A dichos foros asisten únicamente los consejeros regionales de Coquimbo - a veces, un gobernador o el secretario regional ministerial de Agricultura- y las contrapartes del gobierno de San Juan y las instituciones argentinas involucradas, pero los representantes del sector directamente afectado no son convocados. Esto es algo a mejorar. Así como la experiencia de la interrupción de 2001 demostró la relevancia de la participación subestatal a través del Comité de Integración, la interrupción de 2020 generó dudas y malestar en los crianceros, debido a que no fueron partícipes desde un primer momento. Incorporar al sector en las reuniones técnicas haría más transparente el proceso, ayudando a mejorar la comunicación respecto del trabajo que se hace para habilitar las veranadas cada año.

\footnotetext{
${ }^{38}$ Entrevista a Luis E. Valdebenito, titular de la Oficina de Integración de la Región de Coquimbo con la Provincia de San Juan, San Juan (1 de diciembre de 2014).

${ }^{39}$ Entrevista a María Teresa Infante, embajadora y exdirectora de Fronteras y Límites del Estado del Ministerio de Relaciones Exteriores de Chile, La Haya (13 de octubre de 2014).
} 


\section{Referencias bibliográficas}

Alvarez, M. (2019). En búsqueda de institucionalizar la paradiplomacia: la experiencia argentinochilena. En M. Alvarez, M. Luna Pont y N. Oddone (eds.), América Latina global. Estudios regionales sobre paradiplomacia (pp. 243-274). Sáenz Peña: Universidad Nacional de Tres de Febrero.

Alvarez, M. (2020). La incorporación de lo subestatal en la relación argentino-chilena: Los comités de integración y la reunión de intendentes y gobernadores. Economía y Política, 7(1), 95122. Recuperado de https://doi.org/10.15691./07194714.2020.004

Alvarez, M. (2021). Debates teóricos sobre la acción exterior de los gobiernos no centrales. Una propuesta sintetizadora respecto de la paradiplomacia. Papel Político, 26(2), en prensa.

Armaza, C. (12 de diciembre de 2020). Argentina autoriza veranadas, aunque limita en 20 mil los animales que podrán subir. El Día. Recuperado de http://www.diarioeldia.cl/economia/argentina-autoriza-veranadas-aunque-limita-en-20mil-animales-que-podran-subir

De Irigoyen, B. (1881). La cuestión de límites entre la República Argentina y Chile. Buenos Aires: Impr. de La República.

Diario La Región de Coquimbo. (12 de enero de 2020). Falta de lluvia en la cordillera hace peligrar las veranadas de este año. Diario La Región de Coquimbo. Recuperado de https://www.diariolaregion.cl/falta-de-lluvia-en-la-cordillera-hace-peligrar-las-veranadasde-este-ano/

Diario Popular. (1 de enero de 2021). Cierre de fronteras en Argentina retrasa ingreso de crianceros Chilenos para las veranadas. Diario Popular. Recuperado de https://www.diariopopular.cl/2021/01/01/cierre-de-fronteras-en-argentina-retrasa-ingresode-crianceros-chilenos-para-las-veranadas/

División de Planificación Regional. (2020). Documento Guía de Veranadas. Coquimbo: Gobierno Regional de Coquimbo.

Dugini de De Cándido, M. I. (1997). Argentina, Chile, Mercosur: Cambios y continuidades. Buenos Aires: Ciudad Argentina.

El Illapelino. (18 de diciembre de 2020). Crianceros de Choapa podrán transportar un total de 6000 mil caprinos a Argentina durante veranadas. El Illapelino. Recuperado de http://elillapelino.cl/2020/12/18/crianceros-de-choapa-podran-transportar-un-total-de6000-mil-caprinos-a-argentina-durante-veranadas/

El Montepatrino. (14 de octubre de 2020). Solicitan a intendente Pablo Herman buscar vía para la realización de las veranadas en Argentina. El Montepatrino. Recuperado de 
http://elmontepatrino.cl/2020/10/14/solicitan-a-intendente-pablo-herman-buscar-via-parala-realizacion-de-las-veranadas-en-argentina/

Fortin de Iñones, L. (2011). Impuestos sobre el ganado vacuno en Mendoza y Chile. Estudios Avanzados, (15), 31-54.

González, C. (28 de septiembre de 2020). Semana clave para decidir realización de veranadas en pandemia. El Día. Recuperado de http://www.diarioeldia.cl/region/semana-clave-paradecidir-realizacion-veranadas-en-pandemia

González Lorca, S. (5 de noviembre de 2020). Programan encuentros con el Gobierno de San Juan para avanzar en temas de integración. Core. Consejo Regional. Gobierno Regional. Región de Coquimbo. Recuperado de https://www.corecoquimbo.cl/programan-encuentros-conel-gobierno-de-san-juan-para-avanzar-en-temas/corecoquimbo/2020-11-05/144116.html

GORE Coquimbo. (4 de noviembre de 2019). Gobierno plantea soluciones ante modificación de las veranadas. Gobierno Regional. Región de Coquimbo. Recuperado de http://www.gorecoquimbo.cl/gorecoquimbo/site/artic/20191104/pags/20191104133522.ht $\mathrm{ml}$

Iribarren Avilés, R. (2012). Agua Negra. Historias de un camino. La Serena: Editorial del Norte.

Lacoste, P. (1999). El papel de la frontera en las relaciones argentino-chilenas. Diplomacia, (79), 43-58.

Lacoste, P. (2003). La imagen del otro en las relaciones de la Argentina y Chile (1534-2000). Buenos Aires: Fondo de Cultura Económica de Argentina y Universidad de Santiago de Chile.

Lacoste, P. (ed.). (2005). Argentina-Chile y sus vecinos. Tomo I. Mendoza: Caviar Bleu.

Leiva, C. (22 de agosto de 2020). La actividad de las veranadas mueve casi 98 millones de pesos por cada temporada. Diario de Cuyo. Recuperado de https://www.diariodecuyo.com.ar/economia/La-actividad-de-las-veranadas-mueve-casi98-millones-de-pesos-por-cada-temporada-20200821-0102.html

Leiva, C. (16 de enero de 2021). Después de 7 años no habrá temporada de veranadas en los valles cordilleranos. Diario de Cuyo. Recuperado de https://www.diariodecuyo.com.ar/sanjuan/Despues-de-7-anos-no-habra-temporada-deveranadas-en-los-valles-cordilleranos-20210115-0104.html

López Daneri, M. E. y Davire de Musri, D. (2006). Las vías de circulación como factor de integración regional. En A. M. García (ed.), Desde San Juan hacia la historia de la región: Parte I Siglos XVI a XIX (pp. 229-242). San Juan: Universidad Nacional de San Juan. 
Maino, V. (2015). Trashumancia en el Valle del Choapa. Coquimbo: Minera Los Pelambres-Origo Ediciones. Recuperado de https://www.aminerals.cl/media/4886/libro-arrieros-web.pdf

Morales, A. (1 de noviembre de 2019). Se concretó la firma del acta de veranadas para la temporada 2019-2020. Si San Juan. Servicio Informativo Gobierno de San Juan. Recuperado de https://sisanjuan.gob.ar/gobernador/2019-11-02/18450-firma-de-acta-deveranadas-2019-2020

Navea, R. (15 de diciembre de 2020). Crianceros de la región comenzarían veranadas la primera semana de enero. El Día. Recuperado de http://www.diarioeldia.cl/economia/criancerosregion-comenzarian-veranadas-primera-semana-enero

Orrego Luco, L. (1902). Los problemas internacionales de Chile: La cuestión argentina. La Patagonia hasta el tratado de 1881. Santiago: Esmeralda.

Pecker, A. E. (2007). Fiebre aftosa: Su paso por la Argentina. Buenos Aires: SENASA-Servicio Nacional de Sanidad y Calidad Agroalimentaria.

Pizarro, R. (5 de diciembre de 2019). Estiman que bajará en un 30\% las cabezas de ganado que sube a veranadas. $\quad$ El Ovallino. Recuperado de http://www.elovallino.cl/provincia/limari/estiman-que-bajara-en-30-cabezas-ganado-quesube-veranadas

Radio Montecarlo. (15 de diciembre de 2020). Autoridades regionales firman acuerdo que permitirá la realización de las veranadas en los valles de Calingasta. Radio Montecarlo FM. Recuperado de https://www.radiomontecarlo.cl/autoridades-regionales-firman-acuerdoque-permitira-la-realizacion-de-las-veranadas-en-los-valles-de-calingasta/

Región Binacional. (10 de diciembre de 2020). Paso de Agua Negra: San Juan y Coquimbo esperan la decisión de los gobiernos nacionales para su habilitación. Región Binacional. Recuperado de https:/www.regionbinacional.com/paso-agua-negra-san-juan-coquimboesperan-decision-gobiernos-nacionales-para-habilitacion/

República Argentina y República de Chile. (1881). Tratado de Límites entre la República Argentina y la República de Chile. Recuperado de https://tratados.cancilleria.gob.ar/tratado_ficha.php?id=kqSnlw==

Ríos, C. (4 de noviembre de 2019). Acuerdo permitirá inicio de las veranadas a partir del 15 de diciembre. Core. Consejo Regional. Gobierno Regional. Región de Coquimbo. Recuperado de https://www.corecoquimbo.cl/acuerdo-permitira-inicio-de-las-veranadas-a-partir-del15-de-diciembre/corecoquimbo/2019-11-04/174051.html

Varela, L. (4 de noviembre de 2019). Postergación de veranadas complica el futuro del ganado caprino en la zona. El Día. Recuperado de http://www.diarioeldia.cl/region/postergacionveranadas-complica-futuro-ganado-caprino-en-zona 
Varela, L. (13 de enero de 2021). Veranadas descartadas por cierre de fronteras. El Día. Recuperado de http://www.diarioeldia.cl/region/veranadas-descartadas-por-cierrefronteras

Véliz Codina, S. (2011). Espacio de integración binacional: Los Patos Norte y la veranada. Dos Puntas, 3(4), 49-61.

Venegas, F. (2019). Pensar la integración regional desde los márgenes: la importancia y desafíos de la dimensión subestatal en América Latina desde la experiencia chileno-argentina. Si Somos Americanos. Revista de Estudios Transfronterizos, 19(2), 69-88. DOI: http://dx.doi.org/10.4067/S0719-09482019000200069

Ygobone, A. D. (1971). Soberanía argentina de las Islas Malvinas: Antártida argentina. Cuestiones fronterizas entre Argentina y Chile. Buenos Aires: Editorial Plus Ultra.

\section{Actas}

Acta del Acuerdo de "Reunión Técnica de Veranadas", Pub. L. No. 8397. (2013).

VII Acta del Acuerdo de "Reunión Técnica de Veranadas". (2018).

VIII Acta del Acuerdo de "Reunión Técnica de Veranadas". (2019).

XI Acta del Acuerdo de "Reunión Técnica de Veranadas. (2020).

I Reunión del Comité de Frontera "Paso Agua Negra". (1996).

II Reunión del Comité de Frontera "Paso Agua Negra". (1997).

VI Reunión del Comité de Fronteras "Paso Agua Negra". (1999).

X Reunión del Comité de Frontera "Paso Agua Negra”. (2001).

XI Reunión del Comité de Frontera "Paso Agua Negra”. (2002).

XII Reunión del Comité de Frontera "Paso Agua Negra”. (2003).

XIII Encuentro del Comité de Frontera "Paso Agua Negra”. (2004).

XIV Encuentro del Comité de Frontera "Paso Agua Negra". (2005).

XV Encuentro del Comité de Integración "Paso Agua Negra”. (2006).

XVI Comité de Integración Internacional "Paso Agua Negra”. (2007).

XVII Comité de Integración "Paso Agua Negra”. (2008).

XVIII Comité de Integración "Paso Agua Negra”. (2009).

XIX Comité de Integración "Paso Agua Negra". (2010). 
XX Comité de Integración "Paso Agua Negra”. (2011).

XXI Encuentro del Comité de Integración "Paso Agua Negra”. (2012).

XXII Encuentro del Comité de Integración "Paso Agua Negra". (2013). 